\title{
Three-dimensional Finite Element Analysis of Endodontically Treated Tooth Restored with Carbon and Titanium Posts
}

\section{Özkan ADIGÜZEL ${ }^{1}$, Sadullah KAYA ${ }^{1}$, Senem YİĞİT ÖZER ${ }^{1}$, Yalçın DEĞER ${ }^{2}$, Emine GÖNCÜ BAŞARAN $^{3}$, İzzet YAVUZ ${ }^{4}$}

${ }^{1}$ Assistant Professor, Dicle University, Faculty of Dentistry, Department of Endodontics, Diyarbakir, Turkey

${ }^{2}$ Assistant Professor, Dicle University, Faculty of Dentistry, Department of Prosthodontics, Diyarbakir, Turkey

${ }^{3}$ Research Assistant, Dicle University, Faculty of Dentistry, Department of Prosthodontics, Diyarbakir, Turkey

${ }^{4}$ Associate Professor, Dicle University, Faculty of Dentistry, Department of Pedodontics, Diyarbakir, Turkey

\section{Key Words}

Finite element analysis, carbon post, titanium post

\section{Correspondence: \\ Özkan ADIGÜZEL \\ Dicle University, \\ Faculty of Dentistry, Department of Endodontics, 21280, Diyarbakir, TURKEY. e-mail: dentamania21@hotmail.com}

\begin{abstract}
Aim: This study compared the stress distributions of endodontically treated tooth restored with carbon and titanium post during different loading conditions.

Methodology: A 3-dimensional finite element model was created to represent an endodontically treated maxillary central incisor tooth with its supporting structures. Stress distribution and stress values were then calculated by considering the three dimensional von Mises stress criteria.

Results: A 100-N static vertical occlusal load was applied on the node at the center of occlusal surface of the tooth. The von Mises stress values for carbon post model was on the coronal third and the cervical area of the root in the range of 353.149 and $13.878 \mathrm{MPa}$, for titanium post model was 540.736 and $22.777 \mathrm{MPa}$.

Conclusion: This study shows that the titanium post yields larger stresses than the carbon post.
\end{abstract}

(Int Dent Res 2011;2:55-59)

\section{Introduction}

Endodontically treated teeth are usually weakened because of decay, removal of previous and older restorations and endodontic procedure. Post-and-cores are often required to maintain the final restoration of structurally weakened teeth $(1,2)$.

Generally cast metal dowel and core were used but recently there is an increasing trend towards the use of fiber dowel systems (3). The advance of materials and technology, and in accordance with elevated clinical requirements, new post restoration systems of tooth defect, the non-metal post and core systems, including carbon fiber post system, glass fiber post system and quartz fiber post system, have been introduced into clinical use since early 1990s $(4,5)$.

Prefabricated posts are either metallic posts such as stainless steel, titanium alloy and metal posts, which have been luted with zinc phosphate cement, or non-metallic posts such as posts of zirconia and carbon fiber or glass fiber reinforced resin composite, which are adhesively bonded in the root canal system (6). Fiber dowels provide a more esthetic result than the metallic dowels. They have a modulus of elasticity similar to dentin structure, thus reducing the stress areas at the dowel dentin interface (7). Carbon fiber posts have modulus of elasticity, which is nearly identical to that of dentine and reported to cause less stress in the tooth and root fractures. 
The finite element method (FEM) which has been shown to be a useful tool is a powerful numerical method for solving the differential equations $(8,9)$. The computer program allowed the calculations of stresses, strains, and deformations in discretionally shaped 3D finite element model representing a structure under static loading on tooth-restoration complex $(8,10,11)$

The aim of this study was to evaluate and compare the stress distributions of endodontically treated tooth restored with carbon and titanium post during different loading conditions.

\section{Materials and Methods}

A 3-dimensional finite element model was created to represent an endodontically treated maxillary central incisor tooth with its supporting structures. The model contained a simulated periodontal ligament (PDL) and alveolar bone structure (Fig. 1). The root canal was assumed to have been shaped to accommodate a commercially available fiber post.

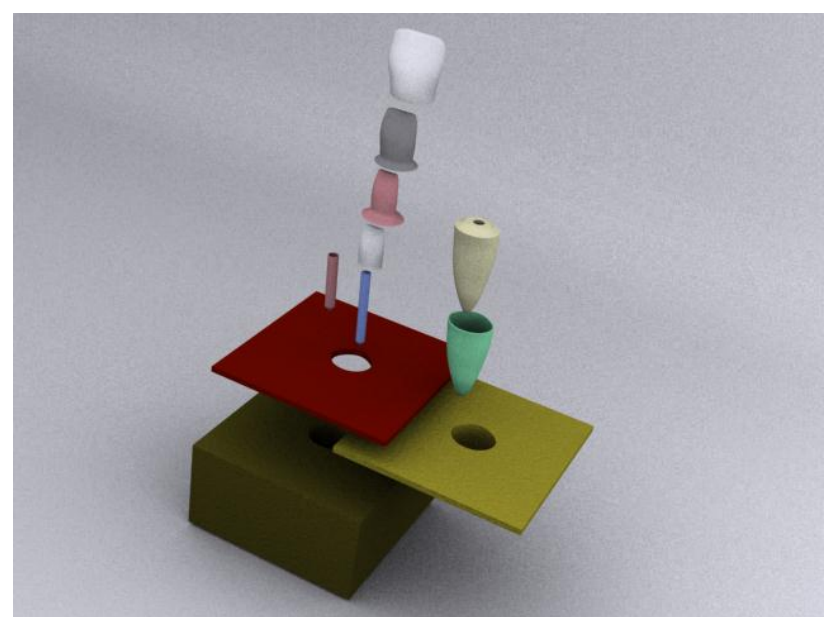

Figure 1. Three-dimensional finite element model and illustration of materials.

All of the materials were assumed to be homogenous, isotropic and linear elastic. Elastic properties of materials (Young's modulus (E) and Poisson's ratio $(\mu)$ ) were assigned according to literature data and given in Table 1. A finite element model was investigated to evaluate how the different occlusal loads changed the stress distribution:

Model: A 100-N static vertical occlusal load was applied on the node at the center of occlusal surface of the tooth (Figure $2 \mathrm{a}$ and $2 \mathrm{~b}$ ).

Rhinoceros 4.0 (3670 Woodland Park Ave N, Seattle, WA 98103 USA) and Algor Fempro (ALGOR, Inc. 150 Beta Drive Pittsburgh, PA 15238-2932 USA) softwares were used for the modelling and stress analysis. Stress distribution and stress values were then calculated by considering the three dimensional von Mises stress criteria.

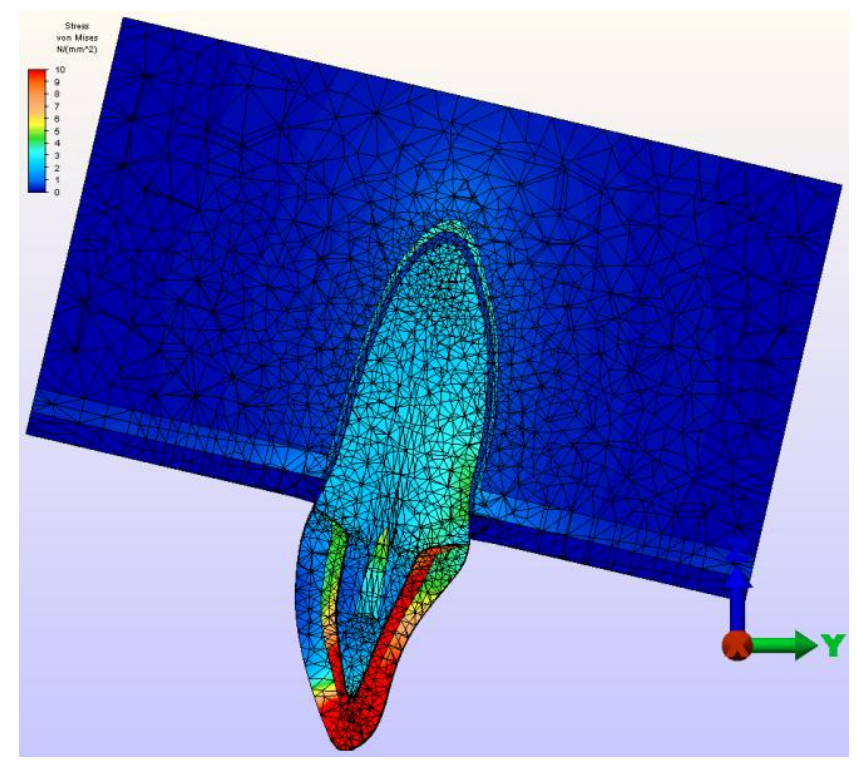

Figure 2a. Three-dimensional Carbon postcore model

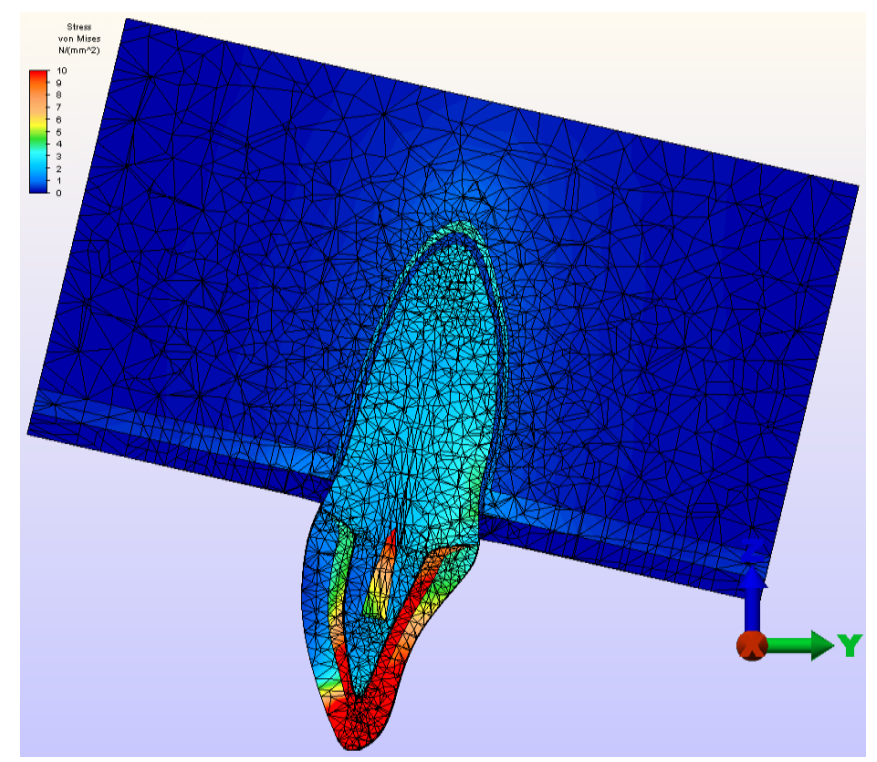

Figure 2b. Three-dimensional Titanium postcore model. 
TABLE 1. The mechanical properties of the materials

\begin{tabular}{|lcc|}
\hline \multicolumn{1}{|c|}{ Material/Component } & Elastic Modulus (MPa) & Poisson Ratio \\
\hline Cortical bone (12) & 13.700 & 0.30 \\
\hline Cancellous bone (12) & 1.370 & 0.30 \\
\hline Dentin (8) & 18.600 & 0.31 \\
\hline Ligament (14) & 68.9 & 0.45 \\
\hline Gingiva (8) & 3 & 0.45 \\
\hline Gutta-percha (12) & 0.69 & 0.45 \\
\hline $\begin{array}{l}\text { Adhesive cement (Panavia, } \\
\text { Kuraray,Japan) (15) }\end{array}$ & 18.600 & 0.28 \\
\hline $\begin{array}{l}\text { Composite core (Clearfil Photo } \\
\text { Core, Kuraray, Japan) }\end{array}$ & 18.600 & 0.26 \\
\hline Nikel-krom (17) & 200.000 & 0.33 \\
\hline Porcelain crown (19) & 68.900 & 0.28 \\
\hline Carbon post (15) & 118.000 & 0.27 \\
\hline Titanium post (8) & 112.000 & 0.33 \\
\hline
\end{tabular}

* Information from company

\section{Results}

The values of stress seen at the middle third of the labial aspect of the root surface. On the contrary, the minimum values were noticed at level of both the apical portion of the post and the root apex. Assessments were made established on the color patterns in Figures $2 a$ and $2 b$ where warm colors denote higher stresses.

Results were presented by considering Von Mises criteria and calculated numerical data were

\section{Discussion}

Restoration of endodontically treated teeth has become an important aspect of dental practice that involves a range of treatment options of variable complexity. Recently, post and core restorations are the option of choice for endodontically treated teeth, but it may makes teeth fragile and more susceptible to fracture (20).

The present study compared the stress distributions of different post systems to identify areas of high stress concentration, where eventual transformed into color graphics to better visualize mechanical stresses in the models. All stress values were indicated in megapascals (MPa).

The analysis of the von Mises stress values for carbon post model showed that maximum stress concentrations were noted on the coronal third and the cervical area of the root in the range of 353.149 and $13.878 \mathrm{MPa}$. Titanium post model showed that maximum stress concentrations were noted on the coronal third and the cervical area of the root in the range of 540.736 and $22.777 \mathrm{MPa}$.

failures are more expected to occur. It was performed to obtain a model of a maxillary central incisor with the surrounding alveolar bone structure.

Glass and carbon posts show high fatigue and tensile strength, and they have a Young's modulus comparable to dentin (16). In addition to, these post systems are compatible with Bis-GMA resin used in bonding procedures and so they can be bonded in root canal with adhesive resin cement and new generation bonding systems which transmit stress between the post and the root structure, reducing stresses and preventing fracture $(13,16)$. 
Under the vertical static loads, teeth restored with fiber posts showed significantly stronger than those with metallic posts. This indicated that under the vertical static loading, metallic posts might cause root fractures in pulpless teeth, but fiber posts neither initiated nor accelerated vertical root fracture (21). The results can be co-related with the modulus of elasticity of carbon fiber.

According to the results of the present study, the mechanical properties and design of the of the post material, and the nature of the material from which the post and core are made very important to the distribution of stress. Finite-element analysis (FEA) has been shown to be a useful technique the analysis of stress distributions (22).

\section{Conclusion}

Within the limitation of this study, it can be concluded that the physical properties of posts were important than on stress distributions in post and core applications. Our study shows that the titanium post yields larger stresses than the carbon post.

\section{Acknowledgments}

The authors deny any conflicts of interest related to this study.

\section{References}

1. Papa J, Wilson PR, Tyas MJ. Pins for direct restorations. Journal of Dentistry 1993;21:259-64.

2. Joshi $S$, Mukherjee $A$, Kheur M, Mehta A. Mechanical performance of endodontically treated teeth. Finite Elements in Analysis and Design 2001;37:587-601.

3. Qualtrough AJ, Mannocci F. Tooth-colored post system: a review. Oper Dent 2003;28: 86-91

4. Purton DG, Love RM. Rigidity and retention of carbon fiber versus stainless steel root canal posts. Int Endodontic J 1996;29:2625.

5. Malquarti G, Berruet RG, Bois D. Prosthetic use of carbon fiber-reinforced epoxy resin for esthetic crowns and fixed partial dentures. J Prosthet Dent 1990;63:251-7.
6. Sahafi A, Peutzfeldt A, Ravnholt G, Asmussen E, Gotfredsen K. Resistance to cyclic loading of teeth restored with posts. Clin Oral Invest 2005;9:84-90

7. Santos AF, Meira JB, Tanaka CB, Xavier TA, Ballester RY, Lima RG, Pfeifer CS, Versluis A. Can fiber posts increase root stresses and reduce fracture? J Dent Res 2010;89:58791.

8. Asmussen E, Peutzfeldt A, Sahafi A. Finite element analysis of stresses in endodontically treated, dowel-restored teeth. J Prosthet Dent 2005;94:321-9.

9. Chen J, Xu L. A finite element analysis of the human temporomandibular joint. J Biomech Eng 1994;116:401-7.

10. Eskitascioglu G, Usumez A, Sevimay $M$, Soykan $E$, Unsal $E$. The influence of occlusal loading location on stresses transferred to implant-supported prostheses and supporting bone: a three-dimensional finite element study. J Prosthet Dent 2004;91:144-150.

11. Eraslan Ö, Eraslan O, Eskitaşcıoğlu G, Belli $S$. Conservative restoration of severely damaged endodontically treated premolar teeth: a FEM study. Clin Oral Invest 2011;15:403-8.

12. Ko CC, Chu, CS, Chung KH, Lee MC. Effects of posts on dentin stress distributions in pulpless teeth, J. Prosthet. Dent., 1992;68: 421-7.

13. Asmussen E, Peutzfeldt A, Heitmann T. Stifness, elastic limit and strength of newer types of endodontic posts. J Dent 1999;27(4):275-8.

14. Holmes, DC, Diaz-Arnold AM, Leary JM, Influence of post dimension on stress distribution in dentin, J. Prosthet. Dent., 1996;75: 140-7.

15. Lanza A, Aversa R, Rengo S, Apicella D, Apicella A. 3D FEA of cemented steel, glass and carbon posts in a maxillary incisor. Dent Mater 2005;21:709-15.

16. Ferrari M, Vichi A, García-Godoy F. Clinical evaluation of fiberreinforced epoxy resin posts and cast post and cores. Am J Dent 2000;13:15B-18B.

17. Hsu, ML, Chen CS, Chen BJ, Huang $\mathrm{HH}$. and CHANG CL. Effects of post materials and length on the stress distribution of endodontically treated maxillary central incisors: a 3D finite element analysis. Journal of Oral Rehabilitation, 2009;36:82130.

18. Toparlı M, Aykul H, Sasaki S. Evaluation of the onset of failure under mechanical and thermal stresses on luting agent for metal- 
ceramic and metal crowns by finite element analysis. J Oral Reh 2003;30:99-105.

19. Geng JP, Tan Keson BC, MSD, and Liu GR. Application of finite element analysis in implant dentistry: A review of the literatüre. J Prosthet Dent 2001;85:585-98.

20. Melo MP, Valle AL, Pereira JR, Bonachela WC, Pegoraro LF, Bonfante G. Evaluation of fracture resistance of endodontically treated teeth restored with prefabricated posts and composites with varying quantities of remaining coronal tooth structure. J. Appl. Oral Sci 2005;13(2):141-6.

21. Hayashi M, Sugeta A, Takahashi $Y$, Imazato $S$, Ebisu S. Static and fatigue fracture resistances of pulpless teeth restored with post-cores. Dent Mater 2008;24:1178-86

22. Lertchirakarn V, Palamara JEA, Messer HH. Patterns of Vertical Root Fracture: Factors Affecting Stress Distribution in the Root Canal. J Endodon 2003;29:523-8. 